OPEN ACCESS

Edited by:

Guangyong Peng,

Saint Louis University, United States

Reviewed by:

Jason Lees,

Uniformed Services University of the Health Sciences, United States

Ping Xie,

Rutgers, The State University of New Jersey, United States

*Correspondence: Zhibin Chen

zchen@med.miami.edu

Specialty section:

This article was submitted to

Cell Death and Survival,

a section of the journal

Frontiers in Cell and Developmental

Biology

Received: 26 January 2021 Accepted: 29 April 2021

Published: 25 May 2021

Citation:

Honan AM and Chen Z (2021)

Stromal Cells Underlining the Paths

From Autoimmunity, Inflammation

to Cancer With Roles Beyond

Structural and Nutritional Support.

Front. Cell Dev. Biol. 9:658984.

doi: 10.3389/fcell.2021.658984

\section{Stromal Cells Underlining the Paths From Autoimmunity, Inflammation to Cancer With Roles Beyond Structural and Nutritional Support}

\author{
Amanda M. Honan ${ }^{1}$ and Zhibin Chen ${ }^{1,2 *}$ \\ 1 Department of Microbiology and Immunology, Miller School of Medicine, University of Miami, Miami, FL, United States, \\ ${ }^{2}$ Sylvester Comprehensive Cancer Center, Miller School of Medicine, University of Miami, Miami, FL, United States
}

Stromal cells provide structural support and nutrients in secondary lymphoid organs and non-lymphoid tissues. However, accumulating evidence suggests that a complex relationship exists between stromal cells and immune cells. Interactions between immune cells and stromal cells have been shown to influence the pathology of both autoimmunity and cancer. This review examines the heterogeneity of stromal cells within the lymph node and non-lymphoid tissues during both homeostatic and inflammatory conditions, in particular autoimmunity and cancer, with the goal of better understanding the complex and apparently paradoxical relationship between these two classes of diseases. The review surveys potential novel mechanisms involving the interactions between stromal cells and immune cells which may contribute to the development, pathology and underlying connection between autoimmunity and cancer, including potential pathways from autoimmune inflammation to either "hot" or "cold" tumors. These interactions may provide some insights to explain the rising incidence of both autoimmunity and cancer in young women in industrialized countries and have the potential to be exploited in the development of new interventions for preventions and treatments of both autoimmune diseases and cancer.

Keywords: stromal cells, secondary lymphoid organs, autoimmunity, cancer, non-lymphoid tissues

\section{INTRODUCTION}

Stromal cells are commonly known for their role in providing support and nutrients in both the secondary lymphoid organs and non-lymphoid tissues. However, recent studies have illustrated the expansive role of stromal cells along with the characterization of the diverse group of cells that constitute the stromal cell compartment. The stromal cell compartment is comprised of many types of cells including but not limited to endothelial cells, mesenchymal stromal cells, and pericytes. Within these larger categories are even more subsets of cells which help shape both the stromal compartment and organ microenvironments (Chang and Turley, 2015; Jalkanen and Salmi, 2020; Krishnamurty and Turley, 2020). This heterogeneity is conserved from the healthy setting to the inflammatory setting such as in autoimmune diseases and cancer (Petrova and Koh, 2018; Koliaraki et al., 2020). Understanding these extensively diverse cell types and their functions and interactions with immune cells in both the healthy setting and the inflammatory setting may help 
better understand the influence of stromal cells in disease pathology, leading to new approaches for the treatment and prevention of inflammatory diseases including autoimmune disorders and cancer, two of the major disease burdens on human beings.

On the "surface" autoimmunity and cancer appear to be at the opposite end of the spectrum of immune-related diseases. Autoimmune diseases are caused by the immune system wreaking havoc on the body's healthy tissues, while cancer represents a failure of the immune system to destroy malignant cells. The recent breakthrough in cancer immune therapy coincidently brought a broader attention to at least one aspect of the intricacy in the relationship between autoimmunity and cancer - autoimmune damage is not just off-target toxicity but also an indicator of effective anti-tumor immunity (Attia et al., 2005; Postow et al., 2018). More perplexingly, there is a long-standing suspicion that autoimmunity might increase the risk of cancer development (Volkers, 1999). That link has been largely regarded with a relevance only to rare cases of cancer, until the recent epidemiological findings of alarming trends of rising cancer incidences in young adults (Anderson et al., 2018; Blaser and Chen, 2018; Kehm et al., 2019; Miller et al., 2020), with the demographic and other evidence from the stomach cancer study suggesting autoimmunity as a potential etiological factor in cancer development at the population level (Anderson et al., 2018; Blaser and Chen, 2018; Kehm et al., 2019; Miller et al., 2020). Whether and how autoimmunity may contribute the rising incidences of early onset cancer in humans remains to be examined. On the other hand, studies using independent approaches with distinct animal models have provided strong evidence for the causality of autoimmune $\mathrm{T}$ cells in cancer development (Nguyen et al., 2013; Miska et al., 2018).

Nevertheless, it remains largely unclear how exactly $\mathrm{T}$ cells in inflammatory settings may promote cancer development. In this review, we explore that question from the angle of the stromal cell biology with a focus on stromal-immune interactions, keeping in mind that the extensive changes in the stromal compartment, such as tissue remodeling and fibrosis, are often associated with both autoimmune disorders and cancer.

\section{HETEROGENEITY OF STROMAL CELLS IN HEALTHY TISSUES}

Stromal cells are essential components in both lymphoid and non-lymphoid tissues. In central lymphoid organs such as the thymus and bone marrow, it has been well-recognized that they play an essential role in supporting lymphocyte development and selection (Petrie and Zuniga-Pflucker, 2007; Mercier et al., 2011). In the periphery, a complex array of stromal cell subsets have been well- characterized. With the constrain of the scope and limitation of our knowledge basis, we will focus this review on the more recent studies on stromal cell and $\mathrm{T}$ lymphocyte interaction in the periphery including lymph nodes and nonlymphoid tissues.

Within the lymph node, stromal cells are derived from either mesenchymal or endothelial origins (Figure 1). These two cell origins can differentiate further into many cell types which include but are not limited to lymphatic endothelial cells (LEC), blood endothelial cells (BEC), fibroblasts, and pericytes. Within these subsets there are even more diversity, as each subset is comprised of a heterogeneous group of cells which can vary in location and function throughout the lymph node (Chang and Turley, 2015; Krishnamurty and Turley, 2020). Stromal cell populations can also be found in non-lymphoid tissues throughout the body. Non-lymphoid tissue stromal cells are also derived from the endothelial and mesenchymal lineages and function similarly to lymph node stromal cells (Koliaraki et al., 2020; Krausgruber et al., 2020). In this section, we will explore the heterogeneity of stromal cells within the lymph node and the non-lymphoid tissues under homeostatic conditions (Table 1).

\section{Endothelial Cell Populations in the Lymph Node}

Lymphatic endothelial cell can be found lining both the afferent and efferent lymphatic vessels. Traditionally, it was believed that their main role was to drain lymph from surrounding tissues in and out of the lymph node, but more recently exciting new functions in antigen presentation and immune tolerance induction have been discovered along with the identification of multiple new subsets of LEC (Jalkanen and Salmi, 2020).

Recent studies in both mice and humans have found transcriptionally distinct populations of LEC residing in distinct geographic location within the lymph node (Iftakhar et al., 2016; Takeda et al., 2019; Fujimoto et al., 2020; Xiang et al., 2020). The lymph node has a series of sinuses which lymph from the afferent lymphatic vessels drains. These sinuses then empty into the efferent lymphatic vessels which carry lymph out of the draining lymph node and to the next lymph node in the chain. These vessels and sinuses are lined with a continuous layer of LEC. Additionally, sites where the lymphatic vessels open into the sinuses contain LEC lined valves (Jalkanen and Salmi, 2020). Within the various vessels, sinuses, and valves are distinct populations of LEC. A study by Iftakhar et al. (2016) found that 400 genes were upregulated and almost 300 genes were downregulated more than eight-fold in pooled cortical and medullary sinus LEC compared to subcapsular LEC. The differentially expressed genes belonged to several different categories including metabolic functions, stress response, and immune response (Iftakhar et al., 2016), indicating the possibility of niche-specific functions of LEC even within the same lymph node. Heterogeneity also exists within the LEC populations in the subcapsular and medullary sinus. Within the subcapsular sinus, ceiling LEC express caveolin-1 (CAV-1) and plasmalemma vesicle-associated protein (PLVAP) which create size exclusion diaphragms and regulate the filtering of soluble antigens into the conduits and the migration of lymphocytes through the LEC floor (Rantakari et al., 2015; Iftakhar et al., 2016; Jalkanen and Salmi, 2020); CSF-1 secretion by floor LEC help maintain the subcapsular macrophage niche (Mondor et al., 2019; Pikor et al., 2021). Ceiling LEC express the atypical chemokine receptor ACKR3 allowing for the scavenging of CCL21 (Ulvmar et al., 2014; Pikor et al., 2021) (Figure 1A). The LEC population 


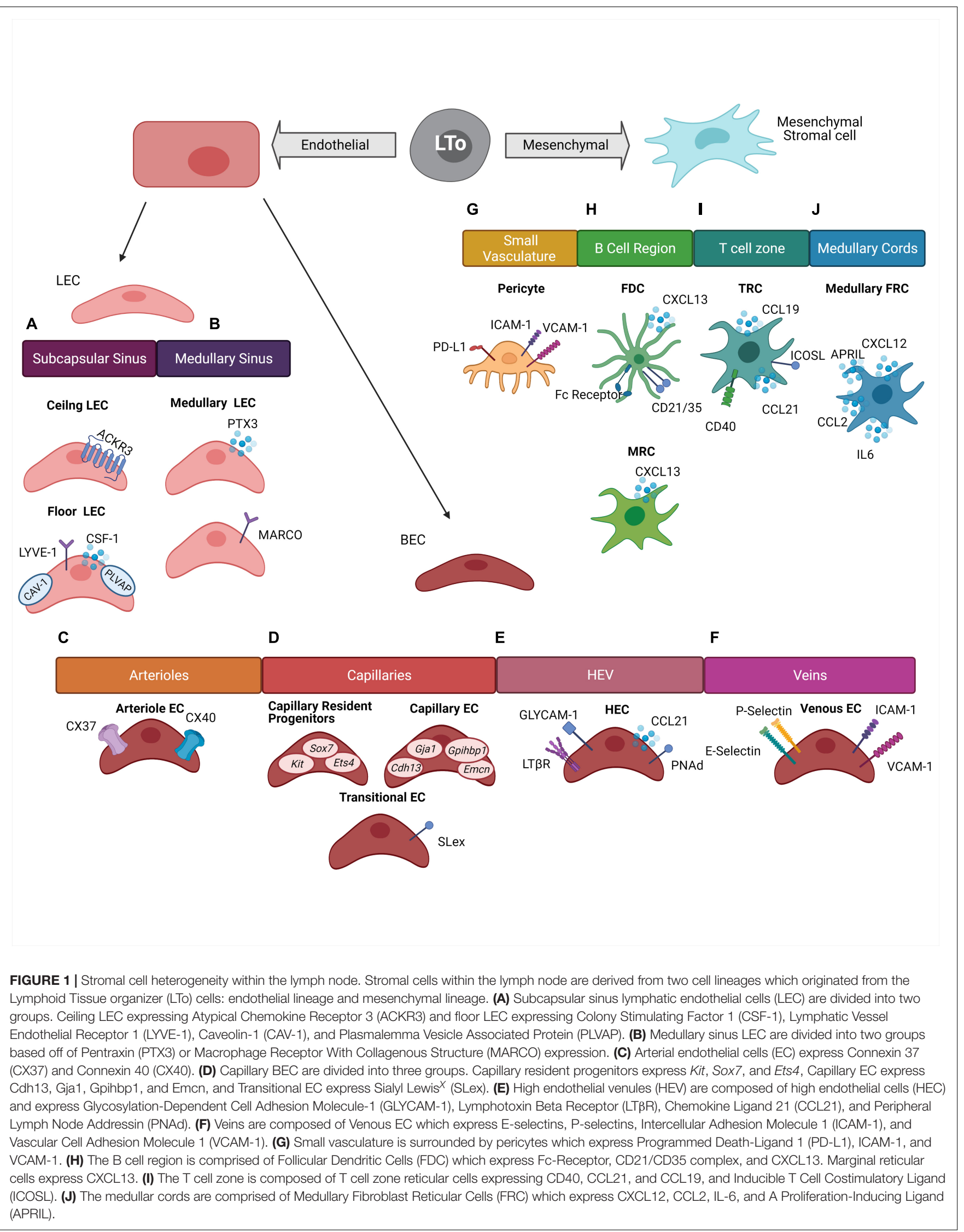


in the medullary sinus can be divided into two groups based on the differential expression of PTX3 and MARCO (Xiang et al., 2020; Pikor et al., 2021) (Figure 1B). It is also now well-recognized that the various LEC subsets have a critical role in antigen presentation (Cohen et al., 2010; Norder et al., 2012; Dubrot et al., 2014; Berendam et al., 2019; Jalkanen and Salmi, 2020). LEC express both the MHC class I (MHCI) and MHC class II (MHCII) molecule. MHCII can be endogenously expressed as well as acquired from dendritic cells through transcytosis (Dubrot et al., 2014). LEC also express molecules such as the transporter associated with antigen processing and the invariant chain indicating the ability for LEC to process and present cytosolic as well as exogenous antigen (Santambrogio et al., 2019).

Lymphatic endothelial cells can serve a critical role in immune tolerance induction through presentation of self-antigens as a potential mechanism of immune regulation. Medullary and cortical LEC can transcribe selected peripheral antigens in an autoimmune regulator (AIRE) independent manner. Peripheral antigens presented by the LEC subset include melanocyte-specific tyrosinase, intestinal epithelial protein A33, and pancreatic prohormone (PYY) (Cohen et al., 2010). LEC also express the inhibitory molecule programmed cell death ligand 1 (PDL1) (Tewalt et al., 2012). PD-L1 expression by LEC has been linked to the potential elimination of autoreactive $\mathrm{CD} 8^{+} \mathrm{T}$ cells (Tewalt et al., 2012). Additionally, LEC play an important role in the migration of $\mathrm{T}_{\text {reg }}$ cells into the lymph node from afferent lymphatic vessels, an important mechanism for establishing tolerance. This migration is dependent on LT $\beta R$ expression by LEC which interact with $L T \alpha \beta$ expressed by $T_{\text {reg }}$ cells. LT $\beta R$ interaction was shown to be not needed for $\mathrm{T}_{\text {reg }}$ migration from the blood through high endothelial venules (HEV), which also express LT $\beta R$, or required by other $\mathrm{T}$ cell populations. These results illustrated a novel mechanism for $\mathrm{T}_{\text {reg }}$ migration through interactions with LEC (Brinkman et al., 2016).

The other major endothelial cell lineage in lymph nodes is BEC. BEC are comprised of two main groups. These groups include the endothelial cells within the HEV and the non-HEV cells. Within the lymph node BEC expand and create a capillary network. This network is responsible for the delivery of solutes, metabolites, and oxygen to the lymphocytes along with control of fluid between tissues. In the lymph node this network of vessels ends at the HEV (Krishnamurty and Turley, 2020), wherein a group of specialized BEC express a family of adhesion molecules and chemokines in order to capture lymphocytes and facilitate their entry into the lymph node. Maintenance of HEV function is necessary for proper trafficking and regulation of lymphocytes (Krishnamurty and Turley, 2020).

Like LEC, BEC are comprised of diverse subsets in terms of both phenotype and function. Brulois et al. (2020) examined sorted BEC populations from the peripheral lymph nodes of mice. Within the BEC population eight transcriptionally distinct subsets were discovered. These subsets included an arteriole endothelial cell population, two venous endothelial cell populations, a high endothelial cell population, a non-high endothelial venous cell population, and five capillary endothelial cell phenotypes (Brulois et al., 2020).
Arteriole endothelial cells express Gja5 and Gja4 which encode connexin 37 (CX37) and connexin 40 (CX40) (Figure 1C). Capillary endothelial cells were identified through the expression of Gja1, Cdh13, Gpihbp1, and Emcn. This gene profile has been previously shown to identify capillary endothelial cells (Lee et al., 2014) (Figure 1D). Within the capillary endothelial cell populations, a transitional capillary phenotype and a resident regenerative population have been identified. The capillary transitional phenotype presented a transcriptional profile as well as a location which was intermediate between the other capillary endothelial cell populations and the high endothelial cells (HEC). This population expressed glycotopes, including 6-sulfo-SLex, which allow for lymphocyte tethering under flow, indicating the ability for lymphocytes to interact with the endothelium prior to entering the HEV (Brulois et al., 2020) (Figure 1D). The resident regenerative capillary population presented features that are commonly exhibited by multipotent progenitor cells. This population expressed genes commonly upregulated in stem cells and progenitor cells such as Sox7, Kit, and Ets4 (Figure 1D). It is believed this population may play a role in basal endothelial proliferation and vascular neogenesis (Brulois et al., 2020). HEC express high levels of peripheral node addressin (PNAd) and CCL21. This expression mediates the entry of naive lymphocytes into the lymph node (Mionnet et al., 2011). HEC also express LT $\beta R$ and glycosylation-dependent cell adhesion molecule 1 (GLYCAM1) (Figure 1E) (Onder et al., 2013; Veerman et al., 2019). Furthermore, medullary venous endothelial cells are characterized by the expression of both E- and P-selectins along with ICAM-1 and VCAM-1 (Figure 1F). It is believed this population may preferentially mediate myeloid cell associated inflammation (Brulois et al., 2020).

\section{Mesenchymal-Derived Cell Populations in the Lymph Node}

During lymph node development mesenchymal cells divide the lymph node into the $\mathrm{B}$ and $\mathrm{T}$ cell regions (Koliaraki et al., 2020). Mesenchymal cells in the B cell domain are characterized as expressing the $\mathrm{B}$ cell attracting chemokine CXCL13 and can further differentiate into marginal reticular cells (MRC) and follicular dendritic cells (FDC). MRC help to support the delivery of antigens to $B$ cells and shape the microenvironment, while FDC specialize in the retention, storage, and presentation of unprocessed antigens to B cells (Heesters et al., 2014; Rodda et al., 2018; Denton et al., 2019) (Figure 1H). Recently, two distinct FDC populations were identified using genetic targeting of the Cxcl13 expressing cells and single cell transcriptomics. The light zone (LZ)-FDC population represented the classical FDC profile expressing both complement and Fc-receptors as well as genes associated with intracellular stiffness. The LZ-FDC gene profile supported the mechanical properties needed to present antigen. The dark zone (DZ)-FDC were shown to express lower levels of these receptors and tended to express a somewhat hybrid phenotype between the LZ-FDC and other B cell region reticular cell (Pikor et al., 2020). 
The mesenchymal-derived cells in the $\mathrm{T}$ cell zone are most commonly referred to as the $\mathrm{T}$ cell zone reticular cells (TRC). This population can be identified by the expression of CCL19 and CCL21 (Rodda et al., 2018). The TRC population forms a meshwork within the $\mathrm{T}$ cell zone attracting both $\mathrm{T}$ cells and dendritic cells and facilitating their interaction. Additionally, TRC can play a role in both inducing an immune response and inducing tolerance (Koliaraki et al., 2020). TRC can express costimulatory molecules such as ICOSL and CD40, or cytokine IL-6 which helps to promote the production of IL-2 and TNF by $\mathrm{CD}^{+} \mathrm{T}$ cells (Brown et al., 2019) (Figure 1I). TRC can also respond to pathogen associated molecular pathways and inflammatory cytokines such as IL-17 (Majumder et al., 2019). On the other hand, the same type of cells can also help induce tolerance within the $\mathrm{T}$ cell population. TRC have the ability to present peripheral tissue antigens within the $\mathrm{T}$ cell zone (Fletcher et al., 2010). These cells also produce nitric oxide (NO) which helps inhibit the proliferation of activated T cells (Siegert et al., 2011). These processes can help attenuate self-reactivity.

A subset of fibroblasts can also be found within the medullary cords which help define and maintain the plasma cell niche (Huang et al., 2018). Similar to other fibroblast cell populations, these cells create a reticular cell network within the medullary cords, but they are functionally distinct from other fibroblastic populations in the $\mathrm{T}$ and $\mathrm{B}$ cell regions of the lymph node. The medullary FRC express soluble proteins such as CXCL12, CCL2, IL-6, and APRIL which fosters the migration, localization, survival, and function of plasma cells (Huang et al., 2018) (Figure 1J).

Importantly, it should be emphasized that cells from the mesenchymal lineage often interact with cells from the endothelial lineage indicating crosstalk between stromal cell populations. Pericytes and BEC are one example of this interaction. Pericytes surround small blood vessels and are essential for vessel maturation and stabilization (Dore-Duffy and Cleary, 2011; Navarro et al., 2016). Angiogenesis begins with the detachment of pericytes from endothelial cells and ends with the stabilization of the new vessel through the recruitment of new pericytes (Jain, 2003). New functional roles of pericytes have also been discovered outside of their structural role. These functions include involvement in immune cell trafficking through the expression of adhesion molecules such as ICAM-1 and VCAM1 , or contributing to the onset of innate immune responses through the expression of various cytokines and chemokines. Alternatively, they may induce $\mathrm{T}$ cell anergy through their expression of PD-L1 (Maier and Pober, 2011; Guijarro-Munoz et al., 2014; Navarro et al., 2016) (Figure 1G). Overall, similar to the endothelial-derived cell populations, the mesenchymalderived cell populations are diverse and influence many different aspects of the immune responses within the lymph node.

\section{Stromal Cells in Healthy Homeostasis of Non-lymphoid Tissues}

The stromal cell populations identified in lymph nodes are also found throughout non-lymphoid tissues. In this setting, stromal cells not only provide a structural and nutritional support for parenchymal tissues, but also help mold the immune profile within various tissues by shaping the transcriptional program of the hematopoietic compartment within each organ. Many of these functions are highly organ specific and help to create an optimal microenvironment for the function of the organ (Krausgruber et al., 2020).

Mesenchymal-derived stromal cells help to shape the organ microenvironment through the production of retinoic acid which regulates innate immune cells in the mucosal lining. For example, retinoic acid production by Wilm's Tumor 1 (WT1) mesothelial and fibroblastic stromal cells helps to maintain both homeostasis and the GATA6 transcriptional program in cavity resident macrophages (Buechler et al., 2019). Additionally, retinoic acid production by stromal cells in the intestinal lamina propria promoted a two-way "crosstalk" between stromal cells and mucosal dendritic cells (Vicente-Suarez et al., 2015). Mesenchymal stromal cells can also promote adaptive immune regulation. In the lung, mesenchymal subsets produce IL33 which creates an immune suppressed environment. This environment supports ILC2s and regulatory $\mathrm{T}$ cell $\left(\mathrm{T}_{\text {reg }}\right)$ differentiation and is crucial for proper function of the lung (Dahlgren et al., 2019).

Mesenchymal stromal cells are also important in immune cell differentiation as well as tissue health within the liver environment. Hepatic stellate cells, a type of liver-specific stromal cell (pericytes), produce CSF-1, IL-34, and bone morphogenetic proteins which play a role in the differentiation of monocytes into Kupffer cells (Bonnardel et al., 2019). Kupffer cells act as tissue resident macrophages in the liver. These cells are essential in maintaining proper liver function and act as the first line of defense against bacterial infections (Naito et al., 1997).

Most types of non-lymphoid tissues, especially the skin dermis and various mucosal membranes are drained through an extensive network of lymphatic vasculature (Petrova and Koh, 2018). The lymphatic vasculature is lined with heterogeneous populations of LEC with functions specific to their location, with a complexity perhaps best illustrated in the small intestine. Not only do the LEC and other stromal cells in the small intestine vasculature function to transport intestinal fluid and lymph, but they are also involved in the uptake and transport of dietary fats (Bernier-Latmani and Petrova, 2017). In mammals, dietary lipids are packaged as chylomicrons, or large triglyceride loaded particles. These particles can transport more than just triglycerides. Fat soluble vitamins and drugs, along with microbiota products such as LPS can also be transported in this way. Intestinal lymph is then transported to the mesenteric lymph nodes where molecules can be surveyed by the immune system or released into blood circulation (Bernier-Latmani and Petrova, 2017). Importantly, this process allows for lipid soluble drugs to bypass the liver, where they will most likely be degraded, and access their target organ (Petrova and Koh, 2018).

Intestinal lymphatic vessels are also important in the maintenance of tolerance to commensal bacteria and food antigens. $\mathrm{CCR}^{+}$dendritic cells migrate into the intestinal lymphatic system via the CCL21 gradient generated by intestinal LEC. Trafficking of these dendritic cells to the mesenteric lymph node help generate $\mathrm{T}_{\text {reg }}$ cells and induce tolerance 
(Forster et al., 2008; Pabst and Mowat, 2012). Presentation of LEC archived antigens to $\mathrm{CD}_{103}{ }^{+}$dendritic cells allows for the transport of food or pathogen antigens to the mesenteric lymph node (Tamburini et al., 2014) and thus plays a role in the induction of oral tolerance or mucosal immunity.

In summary, a large body of literature evidence gathered in recent studies demonstrates that stromal cell-immune interactions are not only necessary for the proper development and function of immune cells within the lymphoid organs, but also play an essential role in supporting and regulating immunity and tolerance in non-lymphoid target tissues in health.

\section{STROMAL CELLS IN CHRONIC INFLAMMATORY STATES OF AUTOIMMUNITY AND MALIGNANCIES}

Inflammation is an essential defense mechanism to restore tissue homeostasis after injury. It is typically resolved by well-controlled immune responses and the participation of organ protective and/or antimicrobial mediators such as resolvins, protectins, and maresins (Serhan and Levy, 2018). If the initial trigger persists and/or immune dysregulation occurs, chronic inflammation can occur (Nathan and Ding, 2010). This scenario is well-illustrated in autoimmune diseases and cancer, two of the major disease burdens in human populations. Chronic inflammation underlies and perpetuates autoimmune diseases and is also believed to play a major role in the development of cancer (Multhoff et al., 2011; Maria et al., 2018). This process has long been known to involve a variety of cellular and molecular mediators in the immune compartment. With the results from more recent studies, it is now well-recognized that stromal cell interactions with the immune system can contribute to the development and maintenance of the chronically inflamed state (Buckley et al., 2015).

\section{Stromal Cells in Autoimmune Diseases: RA and IBD as Examples}

The initial recognition for a key role of stromal cells in autoimmune diseases came from the finding that a subset of thymic stromal cells, thymic medullary epithelial cells, shape central immune tolerance induction by self-antigen presentation (Anderson et al., 2002). Since then, studies by many groups have established a key role for LNSC as well as stromal cells in target tissues in a number of autoimmune disorders (Pistoia and Raffaghello, 2017; Ramaglia et al., 2021; Royer and Cook, 2021; Sim et al., 2021). In this review, we survey the role of stromal cells in non-lymphoid target tissues identified in two autoimmune diseases, rheumatoid arthritis (RA) and inflammatory bowel disease (IBD) because of the large pool of evidence gathered regarding these two diseases.

Rheumatoid arthritis is an autoimmune disease mainly affecting the body's joints. Unresolved inflammation leads to compromised joint function (Gay et al., 1993), and in severe cases may affect internal organs (Bullock et al., 2018). Synovial fibroblasts, which are derived from the mesenchymal lineage of cells, mediates the inflammation within the joints
(Pap et al., 2000). Single cell transcriptomics have found that this population of fibroblasts is not homogenous. The heterogeneity of this population could be very relevant in the discovery of new therapeutic targets, especially in terms of personalized medicine. In preclinical models, cell transfer studies in mice have shown that adoptive transfer of one subset of fibroblast leads to a pathology similar to RA while adoptive transfer of a second fibroblast population leads to a pathology similar to osteoarthritis which is characterized mainly by cartilage damage and not inflammation (Croft et al., 2019). The RA associated fibroblast population was characterized as $\mathrm{PDPN}^{+} \mathrm{Fap}^{+} \mathrm{THY} 1.1^{+}$ and found to produce cytokines such as IL-6, IL-34, and IL-33. These cytokines are associated with the recruitment of pathogenic CD4 T cells, macrophages, and neutrophils to the synovial space ultimately contributing to inflammation of the joint (Figure 2A). Treatment for RA is complicated, mainly due to the diversity of disease pathology within the patient population. Identification of the stromal cell subsets in the inflamed tissues and better understanding of their role in the microenvironment could aid in the development of new treatments for RA.

The subsets of stromal cells involved in chronic inflammation may vary in different disease settings. In IBD, single cell analysis has found a distinct inflammatory population of mesenchymal stromal cells within the intestine of both mice and humans affected by colitis (Martin et al., 2019). This proinflammatory population was enriched for inflammatory, fibrotic, and cancer associated genes (Martin et al., 2019). In other studies, the LEC population has been shown to plays a role in IBD pathology. In experimental models of colitis, impaired intestinal lymphatic vascular function exacerbates intestinal inflammation and worsens symptoms associated with colitis. D6 decoy chemokine receptor deficiency in mice also causes increased severity of colitis symptoms. This molecule is highly expressed by LEC and is necessary to restrict irregular inflammatory leukocyte adhesion to lymphatic vessels (McKimmie et al., 2013).

Collaboration between stromal cell populations can also exacerbate autoimmune pathology. A single cell analysis of Chron's Disease legions showed signaling between fibroblast and endothelial cells contribute to inflammation within the large intestine lamina propria. The activated fibroblast population produces CCL2 and CCL7 which interacts with ACKR2 on activated endothelial cells. This leads to recruitment of circulating monocytes which differentiate into macrophages. These inflammatory macrophages produce cytokines such as TNF, IL-1 $\beta$, and IL- $1 \alpha$ which further activate the fibroblast population while also recruiting pathogenic CD4 $\mathrm{T}$ cells into the large intestine (Martin et al., 2019) (Figure 2B). Currently treatments for IBD typically target the immune system to dampen chronic inflammation (Axelrad et al., 2016). The efficacy of current interventions can substantially improve if effective approaches can be developed to target the stromal compartment. For that purpose, it is important to understand how the stromal cell compartment and which subset(s) play a major role in perpetuating chronic inflammation.

Taken together evidence from a number of autoimmune disorders, it is now recognized that autoimmune diseases are a major class of inflammatory diseases whose pathology may 


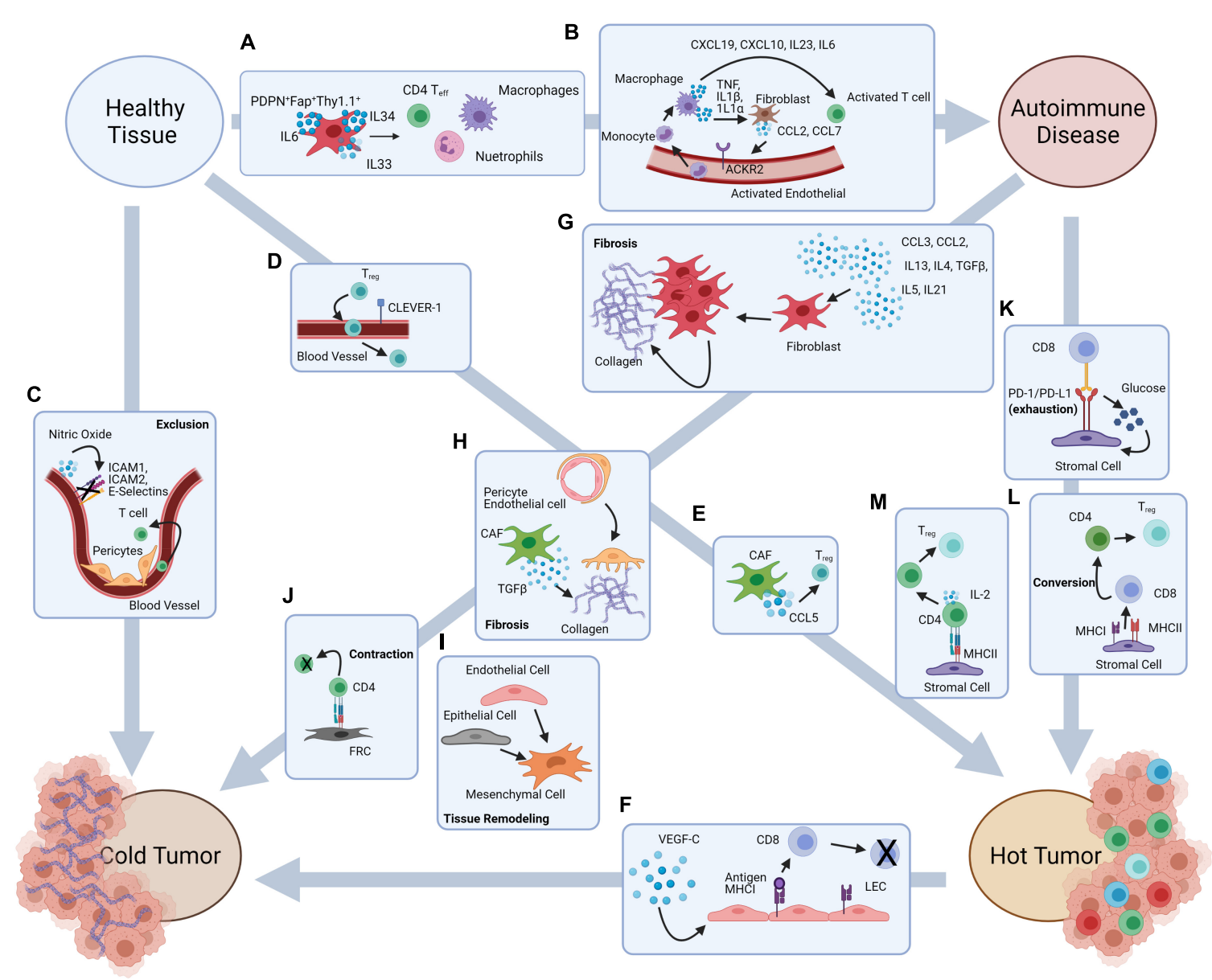

FIGURE 2 | Stromal cell-mediated potential mechanisms underlying the putative pathways from autoimmune damage to cancer development. Autoimmune disease onset and cancer development are both characterized by inflammation and immune dysregulation. Literature evidence suggests some putative pathways that may associate autoimmunity and cancer development, and possibly explains the autoimmune etiology in some types of cancer. (A) Fibroblasts contribute to the recruitment of inflammatory cells in autoimmune disorders such as RA. (B) Activated fibroblasts and endothelial cells contribute to inflammation within the large intestine. (C) Abnormal BEC structure and pericyte interactions lead to T cell exclusion in the TME, while NO production downregulates the expression of adhesion markers on blood vasculature. (D) CLEVER-1 expression by blood vessels leads to $T_{\text {reg }}$ recruitment into the TME. (E) CCL5 production by CAF contribute to $T_{\text {reg }}$ recruitment into the TME. (F) VEGF-C production increases LEC proliferation and antigen presentation leading to CD8 T cell apoptosis. (G) Inflammatory signals lead to fibroblast proliferation and collagen production causing fibrosis. (H) Pericyte transition into fibroblast like cells and TGF $\beta$ expression by CAF contributes to fibrosis. (I) Endothelial cell to mesenchymal cell transition and epithelial to mesenchymal cell transition. (J) Antigen presentation by FRC leads to CD4 T cell contraction. (K) PD-1/PD-L1 interactions leads to metabolic reprograming in both CD8 T cells and stromal cells. (L) MHCl and MHCll expression by stromal cells contributes to CD8 to CD4 lineage conversion. (M) Antigen presentation to CD4 T cells by stromal cells leads to $\mathrm{T}_{\text {reg }}$ differentiation.

be partially caused and exacerbated by the interactions of stromal cells and immune cells. Further investigation into these interactions may increase understanding of the onset and pathology of these heterogeneous diseases, and eventually lead to new avenues for therapeutic development.

\section{Stromal Cells in Cancer}

The role of stromal cells has been generally recognized in the development of cancer; in particular, stromal cells are now well known to have a critical role in both the formation and function of the tumor microenvironment (TME). Within the TME, stromal cells can play an important role in modulating immune cells. TME stromal cells are not derived from a malignant cell lineage; therefore theoretically these cells should function similarly to their counterparts in healthy tissues (Turley et al., 2015). However, recent studies have shown that this is not the case. Although the stromal cells within the TME may not be malignant, their function tends to be altered within the tumor tissues. These alterations can affect the function of lymphocytes within the TME and influence tumor growth, metastasis, and chemoresistance (Turley et al., 2015). It can also be theorized that stromal cell alterations may contribute to the development of either "hot" or "cold" tumors, or potentially the conversion between the two.

The BEC subset plays an important role in the migration of immune cells into tissues. Within the tumor, it has been shown 
that trafficking of antigen specific T cells is dysfunctional. Some of this immune trafficking dysfunction can be contributed to abnormal structure of vasculature within the tumor (Griffioen et al., 1996a). Tumor BEC are irregularly shaped and have loose intercellular connections while pericytes are also abnormal within tumor vessels. Pericytes loosely associate with the BEC and the basement membrane which contributes to the leakiness of tumor vasculature (Castermans and Griffioen, 2007). The effects of the abnormal structure of tumor vasculature are exacerbated by a change in the adhesive properties of these cells. It has been shown that BEC within the tumor vasculature have reduced expression of E-selectin. This reduction leads to impaired lymphocyte recruitment. Tumor BEC also poorly express ICAM-1, ICAM2, and VCAM-1 (Griffioen et al., 1996a). These molecules are involved in lymphocyte extravasation from circulation into tissues. Changes in NO production by vasculature stroma can also affect lymphocyte adhesion and extravasation. NO production helps maintain the vasculature in a resting state. During homeostatic conditions, production of NO by BEC inhibits lymphocyte tissue infiltration (Griffioen et al., 1996b). Within the TME several factors can alter the production of NO. These factors include VEGF-A and fibroblast growth factor 2 (FGF2) which stimulate NO synthases leading to the catalysis of NO production by BEC. This process leads to the inhibition of endothelium activation and reduced expression of adhesion molecules (Bouzin et al., 2007) (Figure 2C).

Evidence has also been found to suggest tumor endothelium favors the extravasation of immunosuppressive lymphocyte populations such as $\mathrm{T}_{\text {reg }}$ cells. Of note, $\mathrm{T}_{\text {reg }}$ infiltration has been associated with decreased survival in many types of cancer. One example is the increased expression of CLEVER-1 in the BEC population found in human hepatocellular carcinoma. CLEVER1 was found to preferentially mediate the infiltration of $\mathrm{T}_{\text {reg }}$ populations into the tumor (Shetty et al., 2011) (Figure 2D). Cancer associated fibroblasts (CAF) also play a role in $\mathrm{T}_{\text {reg }}$ recruitment. CAF are defined as being $\mathrm{FAP}^{+} \alpha \mathrm{SMA}^{+}$and are the most abundant stromal cell population within the tumor microenvironment (Kalluri and Zeisberg, 2006). In mammary carcinoma increased CCL5 production by CAF is associated with increased $\mathrm{T}_{\text {reg }}$ recruitment, which may in turn facilitate the growth of tumors by effecting the anti-tumor immune response within the TME (Tan et al., 2011) (Figure 2E).

Modulation of immune cell recruitment to the TME is not the only way stromal cells can impinge on the immune profile. Stromal cells can alter tolerance induction and immune cell differentiation within the TME. LEC in melanoma have the ability to directly modulate the adaptive immune response within the tumor microenvironment. A study by Lund et al. (2012) found when the LEC population was genetically engineered to express VEGF-C, a lymphangiogenic factor which correlates with metastasis and poor prognosis, the antitumor immunity response was hindered. This hindrance was due to the cross-presentation of tumor antigens by the LEC population ultimately leading to the apoptosis of antigen specific $\mathrm{CD}^{+} \mathrm{T}$ cells and tolerance induction to tumor antigens (Lund et al., 2012) (Figure 2F). Deletion of lymphocyte populations within the TME may be one potential mechanism leading to the conversion of a "hot" tumor, which contains immune cells in the TME, to its "cold" counterpart which is characterized as being void of immune cells (Duan et al., 2020).

\section{STROMAL-IMMUNE INTERACTION UNDERPINNING THE PATHWAYS FROM AUTOIMMUNITY, INFLAMMATION TO CANCER}

While autoimmunity may function as a "double agent" in cancer (Multhoff et al., 2011; Toomer and Chen, 2014; Maria et al., 2018) and its anti-tumor effect may indeed involve stromal damages or alteration, this review explores potential mechanisms of altered stromal-immune interaction in autoimmune inflammation that leads to tumorigenesis. We focus on a few of the many potential new mechanisms, keeping in mind the limitation of our scope of knowledge, on how stromal cell pathobiology may underline the immunological and metabolic pathways from autoimmunity, inflammation to cancer.

\section{Stromal Pathology Shared in Autoimmunity and Cancer: Fibrosis and Tissue Remodeling}

At the histopathological level, among the most conspicuous alterations shared by autoimmune diseases and cancer are tissue fibrosis and tissue remodeling. Chronic tissue damage by autoimmune inflammation leads to fibrosis and tissue remodeling. Fibrosis and tissue remolding are also hallmarks of malignance pathology, but whether and how the fibrosis and tissue remodeling initiated by autoimmune damage might contribute to cancer development is still unknown.

Fibrosis is characterized as the deposition of collagen and other extracellular matrix components leading to a buildup of fibrous connective tissues. During chronic inflammatory damage, the stromal cell compartment adapts to the fibrotic development to fortify the tissue barrier and prevent catastrophic breaches, a process that also leads to remodeling of the parenchymal tissues, and potential disrupted organ function (Wynn, 2007; Zhang and Zhang, 2020). It has also been shown to contribute to tumor development, but the exact mechanisms remain largely unknown (Yamauchi et al., 2018). Nevertheless, the immunological consequences of chronic fibrosis can be speculated, such as lost immunogenicity besides the physical impediment of immune-tumor interactions. It is known that effective antitumor immunity can be elicited by targeting either self-antigens or tumor-specific antigens, the latter of which is rare among the abundance of the former. So how could the tumor cell lineage develop in the setting of potent immune cells against the specific self-antigens? Could it be possible that tissue remolding and the development of fibrotic tissues in the autoimmune setting leads to the down regulation of these specific autoantigens in turn allowing tumor cells to escape detection? In other words, could the chronic autoimmune destruction "edit" out the cells expressing the target antigens and eventual lineage escape due to 
TABLE 1 | Heterogeneity in function of lymph node and non-lymphoid tissue stromal cells.

\begin{tabular}{|c|c|c|c|c|c|c|c|c|c|c|}
\hline \multirow[t]{2}{*}{ Cell Type } & \multirow[t]{2}{*}{ Lineage } & \multirow[t]{2}{*}{ Site } & \multicolumn{8}{|c|}{ Function } \\
\hline & & & $\begin{array}{c}\text { Fluid } \\
\text { drainage }\end{array}$ & $\begin{array}{l}\text { Lymphocyte } \\
\text { trafficking }\end{array}$ & $\begin{array}{l}\text { Nutrient } \\
\text { delivery }\end{array}$ & $\begin{array}{c}\text { Antigen } \\
\text { presentation }\end{array}$ & $\begin{array}{l}\text { Tolerance } \\
\text { induction }\end{array}$ & $\begin{array}{c}\text { Immune } \\
\text { suppression }\end{array}$ & $\begin{array}{l}\text { Innate } \\
\text { immune } \\
\text { response }\end{array}$ & $\begin{array}{l}\text { Angio- } \\
\text { genesis }\end{array}$ \\
\hline $\begin{array}{l}\text { Lymphatic } \\
\text { Endothelial Cell }\end{array}$ & Endothelial & Line lymphatic vessels & $x$ & $x$ & $x$ & $x$ & $x$ & $x$ & $x$ & \\
\hline $\begin{array}{l}\text { Blood Endothelial } \\
\text { Cell }\end{array}$ & Endothelial & Line blood vessels & $x$ & $x$ & $x$ & & & & $x$ & $x$ \\
\hline Fibroblast & Mesenchymal & $\begin{array}{l}\text { B cell region, T cell zone, } \\
\text { medullary cord, various } \\
\text { non-lymphoid tissue }\end{array}$ & & $x$ & & $x$ & $x$ & $x$ & $x$ & \\
\hline Pericyte & Mesenchymal & $\begin{array}{l}\text { Surrounding small blood } \\
\text { vessels }\end{array}$ & & $x$ & & & & $x$ & $x$ & $x$ \\
\hline
\end{tabular}

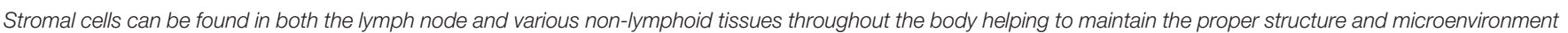

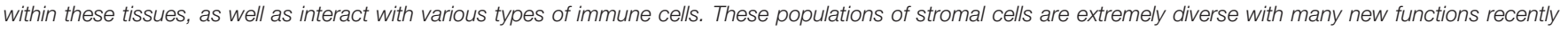

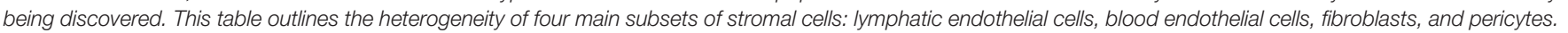

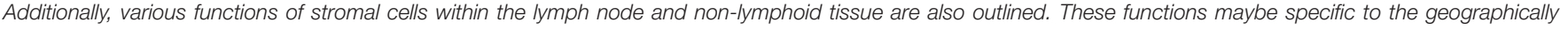
location of the stromal cell subset.

their lack of self-antigens recognized by the specific autoimmune T cells?

Inflammation and tissue damage repair are essential mechanisms of homeostatic maintenance. During acute inflammatory events tissue damage is repaired in a controlled and systematic manner. However, during chronic inflammation these mechanisms are often disrupted. For instance, fibrotic tissue development often occurs in patients suffering from IBD, an autoimmune disease which also has links to cancer development (Rieder and Fiocchi, 2009). Moderate fibrosis is a normal occurrence in a majority of patients suffering from IBD. In these cases, the fibrosis does not show any clinical manifestations, but approximately $30 \%$ of cases experience severe fibrosis (Silverstein et al., 1999). It has traditionally been believed that fibrosis is caused by chronic exposure to inflammation which cause fibroblasts to proliferate and deposit collagen leading to the development of scar tissues over an extended period of time (Figure 2G). This view of fibrosis often simplifies the complicated process which involves not just fibroblasts, but also other stromal cells along with many different immune cells, cytokines, and chemokines (Rieder and Fiocchi, 2009). For example, pericytes have been found to contribute to fibrosis, especially in the skin. Pericytes have the ability to differentiate into fibroblast like cells as a response to inflammation. During these events pericytes detach from endothelial cells, migrate into the surrounding tissues and produce collagen ultimately contributing to fibrosis in these tissues (Sundberg et al., 1996) (Figure 2H).

As mentioned in earlier sections stromal cells are derived from either the mesenchymal or the endothelial cell lineages. In the case of fibrosis, transformations of stromal cell lineages can occur even though stromal cells in tumors may not necessarily originate from the malignant lineage. During the transformation fibroblasts are generated from cells which did not originate from the mesenchymal origin. The transformation processes include epithelial-to-mesenchymal transition and endothelial-to-mesenchymal transition (Frid et al., 2002; Kalluri and Neilson, 2003) (Figure 2I).
Many of the mediators needed for these transitions are present in the autoimmune setting. Additionally, the populations of cells undergoing transformations are extremely heterogeneous with various functions.

Investigation into which subsets of stromal cells may undergo transformation could help to develop new therapies with more specific targets. These cell lineage transformations can also contribute to tumor malignance, especially in light of their interaction with immune cells, although these interactions can often be complicated and vary in different disease settings (Cho et al., 2018; Choi et al., 2020). For instance, $\mathrm{T}_{\text {reg }}$ have been shown to be pro-fibrotic in some disease states, and anti-fibrotic in other disease states (Zhang and Zhang, 2020). Metabolites, cytokines or growth factors from parenchymal or inflammatory cells may also influence the lineage fate of stromal cells. Therefore, it is important to understand these complex relationships and interactions between immune cells, their byproducts, and stromal cells in order to better understand how the process of fibrosis development and tissue remolding may underlie the development of cancer in the autoimmune setting.

\section{Potential Effect of Inflammatory Stromal Responses on T Cell Exhaustion, Lineage Conversion and Exclusion From Autoimmunity to Cancer}

Immune dysregulation of $\mathrm{T}$ cells plays a key role in initiation, execution and perpetuation of autoimmune tissue damage. Abnormal or ineffective $\mathrm{T}$ cell response is also a key feature of cancer and a target of immune therapy. Given the alteration of stromal cell contexture by inflammation, fibrosis and tissue remodeling in both autoimmune diseases and cancer, it is conceivable that $\mathrm{T}$ cell regulation and/or dysfunction impinged by the stromal-immune interaction in autoimmune settings are projected to malignant tissues, not only likely in "hot" tumors that have abundant yet ineffective in situ immune reaction, but also possibly in "cold" tumors that are largely devoid of inflammatory infiltrates (Figure 2). 
Autoimmune $\mathrm{T}$ cells can drive inflammatory tissue damage and initiate cancer development (Nguyen et al., 2013; Miska et al., 2018). The exact state of the $\mathrm{T}$ cell differentiation in the autoimmune and tumorigenic conditions remains to be characterized. Recent studies have brought attention to a state of $\mathrm{T}$ cell differentiation called exhaustion in chronic inflammatory settings (Wherry, 2011). And indeed, T cell exhaustion may be a new potential mechanism that helps connect the "dots" between autoimmunity and cancer. $\mathrm{T}$ cell exhaustion is commonly seen during chronic infection and in the TME. Exhaustion occurs when $\mathrm{T}$ cells are exposed to persistent antigen and or inflammatory signals. $\mathrm{T}$ cell exhaustion can be seen in both the CD8 and CD4 $\mathrm{T}$ cell lineages and is marked by both phenotypic and mechanistic difference when compared to other dysfunctional $\mathrm{T}$ cell states. The exhausted $\mathrm{T}$ cells have reduced effector function, memory properties, and increased expression of inhibitory receptors (Wherry, 2011). Additionally, T cell exhaustion can also be seen in the autoimmune setting but is more often viewed positively (McKinney et al., 2015). In this regard, stromal cells could potentially drive the switch to the exhausted state in $\mathrm{T}$ cells as a mechanism to control the chronic inflammation. Then, might this mechanism promote the development of cancer within the tissue in the process of progression from chronic inflammation to tumorigenesis?

For many types of cancer in their fully developed states, it is well-recognized that $\mathrm{T}$ cell exhaustion is prevalent and needs to be overcome for the disruption of TME (Jiang et al., 2015; Hashimoto et al., 2018; McLane et al., 2019). Many immunotherapies target co-inhibitory pathways as a way to overcome $\mathrm{T}$ cell exhaustion and promote immunity against cancer or chronic infection (Jiang et al., 2015; Hashimoto et al., 2018; McLane et al., 2019). On the other hand, in the case of autoimmune diseases, exhaustion may improve patient outcome. Untreated patients suffering from an active autoimmune disease who present a transcriptional signature similar to that seen in exhausted $\mathrm{CD} 8 \mathrm{~T}$ cells have a more favorable long-term prognosis. This was seen in antibody associated vasculitis (AAV), IBD, and systemic lupus erythematosus (SLE) (McKinney et al., 2015). Therefore, in the autoimmune diseases, inducing $T$ cell exhaustion could potentially reduce relapse and increase favorable prognosis within patients suffering from active diseases. Interestingly, those exhausted cells may maintain some of their effector function, suggesting that these $T$ cells may not be permanently exhausted or may have the ability to switch between the exhausted and effector states. This could account for the cycle of relapse which is observed in patients suffering from autoimmunity. The role of stromal cells in the induction of $\mathrm{T}$ cell exhaustion during autoimmunity has not been well studied. However, extrapolating from of the functions of stromal cells in the TME it is reasonable to hypothesize that stromal cell interactions with immune cells could play a role in the induction and maintenance of the exhausted $\mathrm{T}$ cell state.

While the molecular nature of $\mathrm{T}$ cell exhaustion in autoimmunity remains to be elucidated, $\mathrm{T}$ cell exhaustion as a hallmark of the TME is well characterized in a number of cellular and molecular aspects, which is believed to be induced by several different mechanisms. The best characterized mechanism is perhaps the PD-1/PD-L1 pathway (Jiang et al., 2015; Hashimoto et al., 2018; McLane et al., 2019). It is well known that the level of expression of PD-L1 on tumor cells correlates with patient prognosis while anti-PD1 immunotherapy has been shown to be successful in many cases (Jiang et al., 2015; Hashimoto et al., 2018; McLane et al., 2019). Less known, and strikingly, is the fact that PD-L1 is abundantly expressed on stromal cells and is often upregulated within the TME, despite the non-malignant origin of the stromal cells (Schworer et al., 2019). PD-1/PD-L1 interactions have been shown to alter glucose metabolism in both the stromal cell and the $\mathrm{T}$ cell subsets, driving $\mathrm{T}$ cells toward the exhausted state. PD-1/PD-L1 interactions enhance glucose uptake of tumor stromal cells while simultaneously decreasing glucose uptake of $\mathrm{T}$ cells. This metabolic reprograming favors an immunosuppressed TME (Schworer et al., 2019) (Figure 2K).

The distinct profiles of cytokine and chemokine expression by stromal cells induced under inflammatory conditions could impact $\mathrm{T}$ cell differentiation much beyond a state of an active effector versus exhaustion. Of note, perturbation of cytokine signals can as profound an effect on $\mathrm{T}$ cell lineage specification even in thymic development of $\mathrm{CD}^{+}$and $\mathrm{CD}^{+} \mathrm{T}$ cells (Etzensperger et al., 2017), the two main lineages of $\mathrm{T}$ cells driven by MHC class I (MHCI) and MHC class II (MHCII), respectively, selection (Doyle and Strominger, 1987; Norment et al., 1988; Veillette et al., 1988), although it has long been thought that lineage commitment, once completed in the thymus, is stable due to unique transcriptional programing ( $\mathrm{He}$ et al., 2005; Sato et al., 2005; Hedrick, 2012). Indeed, CD4 and CD8 T cell lineage plasticity manifest in some peripheral microenvironments (Mucida et al., 2013; Reis et al., 2013; Lui et al., 2015). Of particular relevance to a potential new mechanism of immune regulation, $\mathrm{CD}^{+} \mathrm{T}$ cells have been shown to convert to the $\mathrm{CD} 4^{+} \mathrm{T}$ cell lineage including immune suppressive Foxp $3^{+}$regulatory $\mathrm{T}\left(\mathrm{T}_{\text {reg }}\right.$ ) cells (Lui et al., 2015).

The mechanisms underlying these lineage conversions are still mostly unknown, but there is suggestive evidence for a role of MHC expression in stromal cells. It has been shown that MHCII expression is required for the conversion of $\mathrm{CD}^{+} \mathrm{T}$ cells to CD4 ${ }^{+} \mathrm{T}_{\text {reg }}$ cells in the periphery (Lui et al., 2015). As discussed in previous sections, stromal cells have been found to express MHCII both intrinsically and acquire MHCII extrinsically. It has also been shown that MHCII expression by stromal cells can induce the $\mathrm{T}_{\text {reg }}$ phenotype in conventional $\mathrm{CD} 4^{+} \mathrm{T}$ cells, therefore indicating a potential role for stromal cells to directly influence $\mathrm{T}$ cell lineage commitment in the periphery (Nadafi et al., 2020) (Figures 2L,M). Antigen presentation by stromal cells has also been shown to lead to CD4 $\mathrm{T}$ cell contraction. In a study published by Abe et al. (2014), it was shown that during viral infection antigen presentation by LNSC, specifically FRC, leads to $\mathrm{T}$ cell contraction (Figure 2J). This mechanism may be a potential way to prevent continued CD4 effector $\mathrm{T}$ cell response once antigen has been cleared. It is theorized that this mechanism may also play a role in non-lymphoid tissues (Abe et al., 2014), and therefore could be an important mechanism in the control of autoreactive T cells. Potentially in the autoimmune setting, antigen presentation by fibroblast populations could help to eliminate pathogenic $\mathrm{CD} 4 \mathrm{~T}$ cells, similar to what 
is seen in the lymph node during infection. Alternatively, this mechanism could also underlie the development of cancer from autoimmunity. Deletion of autoreactive $\mathrm{T}$ cells in the autoimmune setting could cause malignant cells to go undetected, promoting the development of cancer. Likewise, stromal cells have also been shown to play a role in immune cell differentiation and recruitment in both the autoimmune and cancer settings (Turley et al., 2015; Petrova and Koh, 2018; Koliaraki et al., 2020). Exploration into these mechanisms could also help better understand the connection between autoimmunity and cancer. For instance, how does the inflammatory environment affect lineage conversion and immune cell differentiation, and how might these changes affect cell function? The answers to these questions may lead to novel therapies for both autoimmune diseases and cancer, especially given with their often shared inflammatory states sustained by immune cells or cytokines.

Of note, in the tumor microenvironment, the presence of the various immune constituents, regardless of effectiveness, characterizes the tumor as "hot" and in general a more likely target responding to immune therapy, unlike its "cold" counterpart that is largely devoid of immune cell infiltrates. How a tumor microenvironment evolves to be immune "cold" remains essentially unknown (Duan et al., 2020)? It is possible that "cold" tumors may not necessarily begin as "cold," especially if it has a potential autoimmune origin. Rather, an active process of immune exclusion may have occurred from autoimmunity to cancer which is possibly contributed by altered stromal cells. In this regard, it is worth noting that in autoimmune arthritis, expression of FAP and PDPN marks a subset of synovial fibroblasts that promote autoimmune inflammatory damage (Croft et al., 2019), while $\mathrm{FAP}^{+} \mathrm{PDPN}^{+}$fibroblasts in the cancer setting may mediate the exclusion of $\mathrm{T}$ cells from tumor infiltration, through TGF $\beta$ signaling and fibrosis as well as nitric oxide-mediated T cell suppression (Monteran and Erez, 2019). Overall, the evidence from autoimmunity and cancer studies, taken together, suggest that stromal cells altered by chronic autoimmune inflammation may play a critical role in underlining the pathways to cancer development in some cases, regardless of the eventual outcome of "hot" or "cold" tumors.

\section{CONCLUSION AND FUTURE DIRECTIONS}

Both autoimmune diseases and cancer are heterogeneous diseases which vary greatly from patient to patient. With this

\section{REFERENCES}

Abe, J., Shichino, S., Ueha, S., Hashimoto, S., Tomura, M., Inagaki, Y., et al. (2014). Lymph node stromal cells negatively regulate antigen-specific CD4+ $\mathrm{T}$ cell responses. J. Immunol. 193, 1636-1644. doi: 10.4049/jimmunol. 1302946

Anderson, M. S., Venanzi, E. S., Klein, L., Chen, Z., Berzins, S. P., Turley, S. J., et al. (2002). Projection of an immunological self shadow within the thymus by the aire protein. Science 298, 1395-1401. doi: 10.1126/science.1075958

Anderson, W. F., Rabkin, C. S., Turner, N., Fraumeni, J. F. Jr., Rosenberg, P. S., and Camargo, M. C. (2018). The changing face of noncardia gastric cancer heterogeneity comes difficulty in identifying common causative mechanisms and universal treatments for either category of the diseases. Nevertheless, recent studies suggest that there may be a number of mechanisms linking these two complicated diseases together. One of the major advances is the discovery of new roles for stromal cells in immunological and metabolic regulation that are far beyond their traditionally assigned functions in providing structural and nutritional support. Thus, stromal cells could present attractive therapeutic targets against both autoimmunity and cancer, with immune therapy as well as metabolic interventions. A better understanding of stromal cell intrinsic and extrinsic regulation of immune cells, such as $\mathrm{T}$ cell exhaustion, contraction or lineage conversion, will likely lead to a plethora of novel therapeutic approaches. New discoveries in metabolic reprograming of both stromal and immune compartments will also likely lead to novel and exciting venues for preventions and treatments of autoimmune disorders and cancer. Those approaches could substantially help curtail the rising incidences of both autoimmunity and cancer, especially among the young, and thus reduce the burden of these two major types of diseases on humanity.

\section{AUTHOR CONTRIBUTIONS}

$\mathrm{AH}$ researched and wrote the manuscript. $\mathrm{AH}$ and ZC designed the figures and conceived the theme and framework. ZC reviewed and edited the manuscript. Both authors contributed to the article and approved the submitted version.

\section{FUNDING}

This work is supported in part by grants from the National Institutes of Health R01AI134903 and R01CA245673.

\section{ACKNOWLEDGMENTS}

We sincerely apologize to many colleagues who have made numerous contributions to these expansive fields yet are not cited due to the constraints of space and limitation of our knowledge scope. Figures are created with BioRender.com.

incidence among US non-hispanic whites. J. Natl. Cancer Inst. 110, 608-615. doi: 10.1093/jnci/djx262

Attia, P., Phan, G. Q., Maker, A. V., Robinson, M. R., Quezado, M. M., Yang, J. C., et al. (2005). Autoimmunity correlates with tumor regression in patients with metastatic melanoma treated with anti-cytotoxic T-lymphocyte antigen-4. J. Clin. Oncol. 23, 6043-6053. doi: 10.1200/jco.2005.06.205

Axelrad, J. E., Lichtiger, S., and Yajnik, V. (2016). Inflammatory bowel disease and cancer: the role of inflammation, immunosuppression, and cancer treatment. World J. Gastroenterol. 22, 4794-4801. doi: 10.3748/wjg.v22.i20.4794

Berendam, S. J., Koeppel, A. F., Godfrey, N. R., Rouhani, S. J., Woods, A. N., Rodriguez, A. B., et al. (2019). Comparative transcriptomic analysis identifies 
a range of immunologically related functional elaborations of lymph node associated lymphatic and blood endothelial cells. Front. Immunol. 10:816. doi: 10.3389/fimmu.2019.00816

Bernier-Latmani, J., and Petrova, T. V. (2017). Intestinal lymphatic vasculature: structure, mechanisms and functions. Nat. Rev. Gastroenterol. Hepatol. 14, 510-526. doi: 10.1038/nrgastro.2017.79

Blaser, M. J., and Chen, Y. (2018). A new gastric cancer among us. J. Natl. Cancer Inst. 110, 549-550. doi: 10.1093/jnci/djx279

Bonnardel, J., T’Jonck, W., Gaublomme, D., Browaeys, R., Scott, C. L., Martens, L., et al. (2019). Stellate cells, hepatocytes, and endothelial cells imprint the kupffer cell identity on monocytes colonizing the liver macrophage niche. Immunity 51, 638.e9-654.e9.

Bouzin, C., Brouet, A., De Vriese, J., Dewever, J., and Feron, O. (2007). Effects of vascular endothelial growth factor on the lymphocyte-endothelium interactions: identification of caveolin-1 and nitric oxide as control points of endothelial cell anergy. J. Immunol. 178, 1505-1511. doi: 10.4049/jimmunol. 178.3.1505

Brinkman, C. C., Iwami, D., Hritzo, M. K., Xiong, Y., Ahmad, S., Simon, T., et al. (2016). Treg engage lymphotoxin beta receptor for afferent lymphatic transendothelial migration. Nat. Commun. 7:12021.

Brown, F. D., Sen, D. R., LaFleur, M. W., Godec, J., Lukacs-Kornek, V., Schildberg, F. A., et al. (2019). Fibroblastic reticular cells enhance T cell metabolism and survival via epigenetic remodeling. Nat. Immunol. 20, 1668-1680. doi: 10.1038/ s41590-019-0515-x

Brulois, K., Rajaraman, A., Szade, A., Nordling, S., Bogoslowski, A., Dermadi, D., et al. (2020). A molecular map of murine lymph node blood vascular endothelium at single cell resolution. Nat. Commun. 11:3798.

Buckley, C. D., Barone, F., Nayar, S., Benezech, C., and Caamano, J. (2015). Stromal cells in chronic inflammation and tertiary lymphoid organ formation. Annu. Rev. Immunol. 33, 715-745. doi: 10.1146/annurev-immunol-032713-120252

Buechler, M. B., Kim, K. W., Onufer, E. J., Williams, J. W., Little, C. C., Dominguez, C. X., et al. (2019). A stromal niche defined by expression of the transcription factor WT1 mediates programming and homeostasis of cavityresident macrophages. Immunity 51, 119.e5-130.e5.

Bullock, J., Rizvi, S. A. A., Saleh, A. M., Ahmed, S. S., Do, D. P., Ansari, R. A., et al. (2018). Rheumatoid arthritis: a brief overview of the treatment. Med. Princ. Pract. 27, 501-507. doi: 10.1159/000493390

Castermans, K., and Griffioen, A. W. (2007). Tumor blood vessels, a difficult hurdle for infiltrating leukocytes. Biochim. Biophys. Acta 1776, 160-174. doi: 10.1016/j.bbcan.2007.07.005

Chang, J. E., and Turley, S. J. (2015). Stromal infrastructure of the lymph node and coordination of immunity. Trends Immunol. 36, 30-39. doi: 10.1016/j.it.2014. 11.003

Cho, J. G., Lee, A., Chang, W., Lee, M. S., and Kim, J. (2018). Endothelial to mesenchymal transition represents a key link in the interaction between inflammation and endothelial dysfunction. Front. Immunol. 9:294. doi: 10.3389/ fimmu.2018.00294

Choi, K. J., Nam, J. K., Kim, J. H., Choi, S. H., and Lee, Y. J. (2020). Endothelial-tomesenchymal transition in anticancer therapy and normal tissue damage. Exp. Mol. Med. 52, 781-792. doi: 10.1038/s12276-020-0439-4

Cohen, J. N., Guidi, C. J., Tewalt, E. F., Qiao, H., Rouhani, S. J., Ruddell, A., et al. (2010). Lymph node-resident lymphatic endothelial cells mediate peripheral tolerance via Aire-independent direct antigen presentation. J. Exp. Med. 207, 681-688. doi: 10.1084/jem.20092465

Croft, A. P., Campos, J., Jansen, K., Turner, J. D., Marshall, J., Attar, M., et al. (2019). Distinct fibroblast subsets drive inflammation and damage in arthritis. Nature 570, 246-251. doi: 10.1038/s41586-019-1263-7

Dahlgren, M. W., Jones, S. W., Cautivo, K. M., Dubinin, A., Ortiz-Carpena, J. F., Farhat, S., et al. (2019). Adventitial stromal cells define group 2 innate lymphoid cell tissue niches. Immunity 50, 707.e6-722.e6.

Denton, A. E., Carr, E. J., Magiera, L. P., Watts, A. J. B., and Fearon, D. T. (2019). Embryonic FAP (+) lymphoid tissue organizer cells generate the reticular network of adult lymph nodes. J. Exp. Med. 216, 2242-2252. doi: 10.1084/jem. 20181705

Dore-Duffy, P., and Cleary, K. (2011). Morphology and properties of pericytes. Methods Mol. Biol. 686, 49-68. doi: 10.1007/978-1-60761-938-3_2

Doyle, C., and Strominger, J. L. (1987). Interaction between CD4 and class II MHC molecules mediates cell adhesion. Nature 330, 256-259. doi: 10.1038/330256a0
Duan, Q., Zhang, H., Zheng, J., and Zhang, L. (2020). Turning cold into hot: firing up the tumor microenvironment. Trends Cancer 6, 605-618. doi: 10.1016/j. trecan.2020.02.022

Dubrot, J., Duraes, F. V., Potin, L., Capotosti, F., Brighouse, D., Suter, T., et al. (2014). Lymph node stromal cells acquire peptide-MHCII complexes from dendritic cells and induce antigen-specific CD4(+) T cell tolerance. J. Exp. Med. 211, 1153-1166. doi: 10.1084/jem.20132000

Etzensperger, R., Kadakia, T., Tai, X., Alag, A., Guinter, T. I., Egawa, T., et al. (2017). Identification of lineage-specifying cytokines that signal all CD8(+)cytotoxic-lineage-fate 'decisions' in the thymus. Nat. Immunol. 18, 1218-1227. doi: $10.1038 /$ ni.3847

Fletcher, A. L., Lukacs-Kornek, V., Reynoso, E. D., Pinner, S. E., BellemarePelletier, A., Curry, M. S., et al. (2010). Lymph node fibroblastic reticular cells directly present peripheral tissue antigen under steady-state and inflammatory conditions. J. Exp. Med. 207, 689-697. doi: 10.1084/jem.20092642

Forster, R., Davalos-Misslitz, A. C., and Rot, A. (2008). CCR7 and its ligands: balancing immunity and tolerance. Nat. Rev. Immunol. 8, 362-371. doi: 10 . 1038/nri2297

Frid, M. G., Kale, V. A., and Stenmark, K. R. (2002). Mature vascular endothelium can give rise to smooth muscle cells via endothelial-mesenchymal transdifferentiation: in vitro analysis. Circ. Res. 90, 1189-1196. doi: 10.1161/01. res.0000021432.70309.28

Fujimoto, N., He, Y., D’Addio, M., Tacconi, C., Detmar, M., and Dieterich, L. C. (2020). Single-cell mapping reveals new markers and functions of lymphatic endothelial cells in lymph nodes. PLoS Biol. 18:e3000704. doi: 10.1371/journal. pbio.3000704

Gay, S., Gay, R. E., and Koopman, W. J. (1993). Molecular and cellular mechanisms of joint destruction in rheumatoid arthritis: two cellular mechanisms explain joint destruction? Ann. Rheum. Dis. 52(Suppl. 1), S39-S47.

Griffioen, A. W., Damen, C. A., Blijham, G. H., and Groenewegen, G. (1996a). Tumor angiogenesis is accompanied by a decreased inflammatory response of tumor-associated endothelium. Blood 88, 667-673. doi: 10.1182/blood.v88.2. 667.bloodjournal882667

Griffioen, A. W., Damen, C. A., Martinotti, S., Blijham, G. H., and Groenewegen, G. (1996b). Endothelial intercellular adhesion molecule-1 expression is suppressed in human malignancies: the role of angiogenic factors. Cancer Res. 56, $1111-$ 1117.

Guijarro-Munoz, I., Compte, M., Alvarez-Cienfuegos, A., Alvarez-Vallina, L., and Sanz, L. (2014). Lipopolysaccharide activates Toll-like receptor 4 (TLR4)mediated NF-kappaB signaling pathway and proinflammatory response in human pericytes. J. Biol. Chem. 289, 2457-2468. doi: 10.1074/jbc.m113.521161

Hashimoto, M., Kamphorst, A. O., Im, S. J., Kissick, H. T., Pillai, R. N., Ramalingam, S. S., et al. (2018). CD8 T cell exhaustion in chronic infection and cancer: opportunities for interventions. Annu. Rev. Med. 69, 301-318. doi: 10.1146/annurev-med-012017-043208

He, X., He, X., Dave, V. P., Zhang, Y., Hua, X., Nicolas, E., et al. (2005). The zinc finger transcription factor Th-POK regulates CD4 versus CD8 T-cell lineage commitment. Nature 433, 826-833. doi: 10.1038/nature03338

Hedrick, S. M. (2012). Positive selection in the thymus: an enigma wrapped in a mystery. J. Immunol. 188, 2043-2045. doi: 10.4049/jimmunol.1200077

Heesters, B. A., Myers, R. C., and Carroll, M. C. (2014). Follicular dendritic cells: dynamic antigen libraries. Nat. Rev. Immunol. 14, 495-504. doi: 10.1038/ nri3689

Huang, H. Y., Rivas-Caicedo, A., Renevey, F., Cannelle, H., Peranzoni, E., Scarpellino, L., et al. (2018). Identification of a new subset of lymph node stromal cells involved in regulating plasma cell homeostasis. Proc. Natl. Acad. Sci. U.S.A. 115, E6826-E6835.

Iftakhar, E. K. I., Fair-Makela, R., Kukkonen-Macchi, A., Elima, K., Karikoski, M., Rantakari, P., et al. (2016). Gene-expression profiling of different arms of lymphatic vasculature identifies candidates for manipulation of cell traffic. Proc. Natl. Acad. Sci. U.S.A. 113, 10643-10648. doi: 10.1073/pnas.160235 7113

Jain, R. K. (2003). Molecular regulation of vessel maturation. Nat. Med. 9, 685-693. doi: $10.1038 / \mathrm{nm} 0603-685$

Jalkanen, S., and Salmi, M. (2020). Lymphatic endothelial cells of the lymph node. Nat. Rev. Immunol. 20, 566-578. doi: 10.1038/s41577-020-0281-x

Jiang, Y., Li, Y., and Zhu, B. (2015). T-cell exhaustion in the tumor microenvironment. Cell Death Dis. 6:e1792. doi: 10.1038/cddis.2015.162 
Kalluri, R., and Neilson, E. G. (2003). Epithelial-mesenchymal transition and its implications for fibrosis. J. Clin. Invest. 112, 1776-1784. doi: 10.1172/ jci200320530

Kalluri, R., and Zeisberg, M. (2006). Fibroblasts in cancer. Nat. Rev. Cancer 6, 392-401.

Kehm, R. D., Yang, W., Tehranifar, P., and Terry, M. B. (2019). 40 years of change in age- and stage-specific cancer incidence rates in US women and men. JNCI Cancer Spectr. 3:kz038.

Koliaraki, V., Prados, A., Armaka, M., and Kollias, G. (2020). The mesenchymal context in inflammation, immunity and cancer. Nat. Immunol. 21, 974-982. doi: 10.1038/s41590-020-0741-2

Krausgruber, T., Fortelny, N., Fife-Gernedl, V., Senekowitsch, M., Schuster, L. C., Lercher, A., et al. (2020). Structural cells are key regulators of organ-specific immune responses. Nature 583, 296-302. doi: 10.1038/s41586-020-2424-4

Krishnamurty, A. T., and Turley, S. J. (2020). Lymph node stromal cells: cartographers of the immune system. Nat. Immunol. 21, 369-380. doi: 10.1038/ s41590-020-0635-3

Lee, M., Kiefel, H., LaJevic, M. D., Macauley, M. S., Kawashima, H., O'Hara, E., et al. (2014). Transcriptional programs of lymphoid tissue capillary and high endothelium reveal control mechanisms for lymphocyte homing. Nat. Immunol. 15, 982-995. doi: 10.1038/ni.2983

Lui, J. B., Devarajan, P., Teplicki, S. A., and Chen, Z. (2015). Cross-differentiation from the CD8 lineage to CD4 T cells in the gut-associated microenvironment with a nonessential role of microbiota. Cell Rep. 10, 574-585. doi: 10.1016/j. celrep.2014.12.053

Lund, A. W., Duraes, F. V., Hirosue, S., Raghavan, V. R., Nembrini, C., Thomas, S. N., et al. (2012). VEGF-C promotes immune tolerance in B16 melanomas and cross-presentation of tumor antigen by lymph node lymphatics. Cell Rep. 1, 191-199. doi: 10.1016/j.celrep.2012.01.005

Maier, C. L., and Pober, J. S. (2011). Human placental pericytes poorly stimulate and actively regulate allogeneic CD4 T cell responses. Arterioscler. Thromb. Vasc. Biol. 31, 183-189. doi: 10.1161/atvbaha.110.217117

Majumder, S., Amatya, N., Revu, S., Jawale, C. V., Wu, D., Rittenhouse, N., et al. (2019). IL-17 metabolically reprograms activated fibroblastic reticular cells for proliferation and survival. Nat. Immunol. 20, 534-545. doi: 10.1038/s41590019-0367-4

Maria, A. T. J., Partouche, L., Goulabchand, R., Riviere, S., Rozier, P., Bourgier, C., et al. (2018). Intriguing relationships between cancer and systemic sclerosis: role of the immune system and other contributors. Front. Immunol. 9:3112. doi: 10.3389/fimmu.2018.03112

Martin, J. C., Chang, C., Boschetti, G., Ungaro, R., Giri, M., Grout, J. A., et al. (2019). Single-cell analysis of Crohn's disease lesions identifies a pathogenic cellular module associated with resistance to anti-TNF therapy. Cell 178, 1493.e20-1508.e20.

McKimmie, C. S., Singh, M. D., Hewit, K., Lopez-Franco, O., Le Brocq, M., RoseJohn, S., et al. (2013). An analysis of the function and expression of D6 on lymphatic endothelial cells. Blood 121, 3768-3777. doi: 10.1182/blood-2012$04-425314$

McKinney, E. F., Lee, J. C., Jayne, D. R., Lyons, P. A., and Smith, K. G. (2015). T-cell exhaustion, co-stimulation and clinical outcome in autoimmunity and infection. Nature 523, 612-616. doi: 10.1038/nature14468

McLane, L. M., Abdel-Hakeem, M. S., and Wherry, E. J. (2019). CD8 T cell exhaustion during chronic viral infection and cancer. Annu. Rev. Immunol. 37, 457-495. doi: 10.1146/annurev-immunol-041015-055318

Mercier, F. E., Ragu, C., and Scadden, D. T. (2011). The bone marrow at the crossroads of blood and immunity. Nat. Rev. Immunol. 12, 49-60. doi: 10.1038/ nri3132

Miller, K. D., Fidler-Benaoudia, M., Keegan, T. H., Hipp, H. S., Jemal, A., and Siegel, R. L. (2020). Cancer statistics for adolescents and young adults, 2020. CA Cancer J. Clin. 70, 443-459.

Mionnet, C., Sanos, S. L., Mondor, I., Jorquera, A., Laugier, J. P., Germain, R. N., et al. (2011). High endothelial venules as traffic control points maintaining lymphocyte population homeostasis in lymph nodes. Blood 118, 6115-6122. doi: 10.1182/blood-2011-07-367409

Miska, J., Lui, J. B., Toomer, K. H., Devarajan, P., Cai, X., Houghton, J., et al. (2018). Initiation of inflammatory tumorigenesis by CTLA4 insufficiency due to type 2 cytokines. J. Exp. Med. 215, 841-858. doi: 10.1084/jem.20171971
Mondor, I., Baratin, M., Lagueyrie, M., Saro, L., Henri, S., Gentek, R., et al. (2019). Lymphatic endothelial cells are essential components of the subcapsular sinus macrophage niche. Immunity 50, 1453.e4-1466.e4.

Monteran, L., and Erez, N. (2019). The dark side of fibroblasts: cancerassociated fibroblasts as mediators of immunosuppression in the tumor microenvironment. Front. Immunol. 10:1835. doi: 10.3389/fimmu.2019.01835

Mucida, D., Husain, M. M., Muroi, S., van Wijk, F., Shinnakasu, R., Naoe, Y., et al. (2013). Transcriptional reprogramming of mature CD4(+) helper $\mathrm{T}$ cells generates distinct MHC class II-restricted cytotoxic T lymphocytes. Nat. Immunol. 14, 281-289. doi: 10.1038/ni.2523

Multhoff, G., Molls, M., and Radons, J. (2011). Chronic inflammation in cancer development. Front Immunol 2:98. doi: 10.3389/fimmu.2011.00098

Nadafi, R., Gago, de Graca, C., Keuning, E. D., Koning, J. J., de Kivit, S., et al. (2020). Lymph node stromal cells generate antigen-specific regulatory T cells and control autoreactive T and B cell responses. Cell Rep. 30, 4110.e4-4123.e4.

Naito, M., Hasegawa, G., and Takahashi, K. (1997). Development, differentiation, and maturation of Kupffer cells. Microsc. Res. Tech. 39, 350-364. doi: 10.1002/ (sici) 1097-0029(19971115)39:4<350::aid-jemt5>3.0.co;2-1

Nathan, C., and Ding, A. (2010). Nonresolving inflammation. Cell 140, 871-882. doi: 10.1016/j.cell.2010.02.029

Navarro, R., Compte, M., Alvarez-Vallina, L., and Sanz, L. (2016). Immune regulation by pericytes: modulating innate and adaptive immunity. Front. Immunol. 7:480. doi: 10.3389/fimmu.2016.00480

Nguyen, T. L., Khurana, S. S., Bellone, C. J., Capoccia, B. J., Sagartz, J. E., Kesman, R. A. Jr., et al. (2013). Autoimmune gastritis mediated by CD4+ T cells promotes the development of gastric cancer. Cancer Res. 73, 2117-2126. doi: 10.1158/ 0008-5472.can-12-3957

Norder, M., Gutierrez, M. G., Zicari, S., Cervi, E., Caruso, A., and Guzman, C. A. (2012). Lymph node-derived lymphatic endothelial cells express functional costimulatory molecules and impair dendritic cell-induced allogenic T-cell proliferation. FASEB J. 26, 2835-2846. doi: 10.1096/fj.12-205278

Norment, A. M., Salter, R. D., Parham, P., Engelhard, V. H., and Littman, D. R. (1988). Cell-cell adhesion mediated by CD8 and MHC class I molecules. Nature 336, 79-81. doi: 10.1038/336079a0

Onder, L., Danuser, R., Scandella, E., Firner, S., Chai, Q., Hehlgans, T., et al. (2013). Endothelial cell-specific lymphotoxin-beta receptor signaling is critical for lymph node and high endothelial venule formation. J. Exp. Med. 210, 465-473. doi: 10.1084/jem.20121462

Pabst, O., and Mowat, A. M. (2012). Oral tolerance to food protein. Mucosal Immunol. 5, 232-239. doi: 10.1038/mi.2012.4

Pap, T., Muller-Ladner, U., Gay, R. E., and Gay, S. (2000). Fibroblast biology. Role of synovial fibroblasts in the pathogenesis of rheumatoid arthritis. Arthritis Res. 2, 361-367.

Petrie, H. T., and Zuniga-Pflucker, J. C. (2007). Zoned out: functional mapping of stromal signaling microenvironments in the thymus. Annu. Rev. Immunol. 25, 649-679. doi: 10.1146/annurev.immunol.23.021704.115715

Petrova, T. V., and Koh, G. Y. (2018). Organ-specific lymphatic vasculature: from development to pathophysiology. J. Exp. Med. 215, 35-49. doi: 10.1084/jem. 20171868

Pikor, N. B., Cheng, H. W., Onder, L., and Ludewig, B. (2021). Development and immunological function of lymph node stromal cells. J. Immunol. 206, 257-263. doi: 10.4049/jimmunol.2000914

Pikor, N. B., Morbe, U., Lutge, M., Gil-Cruz, C., Perez-Shibayama, C., Novkovic, M., et al. (2020). Remodeling of light and dark zone follicular dendritic cells governs germinal center responses. Nat. Immunol. 21, 649-659. doi: 10.1038/ s41590-020-0672-y

Pistoia, V., and Raffaghello, L. (2017). Mesenchymal stromal cells and autoimmunity. Int. Immunol. 29, 49-58. doi: 10.1093/intimm/dxx008

Postow, M. A., Sidlow, R., and Hellmann, M. D. (2018). Immune-related adverse events associated with immune checkpoint blockade. N. Engl. J. Med. 378, 158-168. doi: 10.1056/nejmra1703481

Ramaglia, V., Florescu, A., Zuo, M., Sheikh-Mohamed, S., and Gommerman, J. L. (2021). Stromal cell-mediated coordination of immune cell recruitment, retention, and function in brain-adjacent regions. J. Immunol. 206, 282-291. doi: 10.4049/jimmunol.2000833

Rantakari, P., Auvinen, K., Jappinen, N., Kapraali, M., Valtonen, J., Karikoski, M., et al. (2015). The endothelial protein PLVAP in lymphatics controls the entry 
of lymphocytes and antigens into lymph nodes. Nat. Immunol. 16, 386-396. doi: $10.1038 /$ ni.3101

Reis, B. S., Rogoz, A., Costa-Pinto, F. A., Taniuchi, I., and Mucida, D. (2013). Mutual expression of the transcription factors Runx3 and ThPOK regulates intestinal CD4(+) T cell immunity. Nat. Immunol. 14, 271-280. doi: 10.1038/ ni. 2518

Rieder, F., and Fiocchi, C. (2009). Intestinal fibrosis in IBD-a dynamic, multifactorial process. Nat. Rev. Gastroenterol. Hepatol. 6, 228-235. doi: 10. 1038/nrgastro.2009.31

Rodda, L. B., Lu, E., Bennett, M. L., Sokol, C. L., Wang, X., Luther, S. A., et al. (2018). Single-cell RNA sequencing of lymph node stromal cells reveals niche-associated heterogeneity. Immunity 48, 1014.e6-1028.e6.

Royer, D. J., and Cook, D. N. (2021). Regulation of immune responses by nonhematopoietic cells in asthma. J. Immunol. 206, 292-301. doi: 10.4049/ jimmunol.2000885

Santambrogio, L., Berendam, S. J., and Engelhard, V. H. (2019). The antigen processing and presentation machinery in lymphatic endothelial cells. Front. Immunol. 10:1033. doi: 10.3389/fimmu.2019.01033

Sato, T., Ohno, S., Hayashi, T., Sato, C., Kohu, K., Satake, M., et al. (2005). Dual functions of Runx proteins for reactivating CD8 and silencing CD4 at the commitment process into CD8 thymocytes. Immunity 22, 317-328. doi: 10.1016/j.immuni.2005.01.012

Schworer, S., Vardhana, S. A., and Thompson, C. B. (2019). Cancer metabolism drives a stromal regenerative response. Cell Metab. 29, 576-591. doi: 10.1016/j. cmet.2019.01.015

Serhan, C. N., and Levy, B. D. (2018). Resolvins in inflammation: emergence of the pro-resolving superfamily of mediators. J. Clin. Invest. 128, 2657-2669. doi: $10.1172 /$ jci97943

Shetty, S., Weston, C. J., Oo, Y. H., Westerlund, N., Stamataki, Z., Youster, J., et al. (2011). Common lymphatic endothelial and vascular endothelial receptor1 mediates the transmigration of regulatory $\mathrm{T}$ cells across human hepatic sinusoidal endothelium. J. Immunol. 186, 4147-4155. doi: 10.4049/jimmunol. 1002961

Siegert, S., Huang, H. Y., Yang, C. Y., Scarpellino, L., Carrie, L., Essex, S., et al. (2011). Fibroblastic reticular cells from lymph nodes attenuate T cell expansion by producing nitric oxide. PLoS One 6:e27618. doi: 10.1371/journal.pone. 0027618

Silverstein, M. D., Loftus, E. V., Sandborn, W. J., Tremaine, W. J., Feagan, B. G., Nietert, P. J., et al. (1999). Clinical course and costs of care for Crohn's disease: Markov model analysis of a population-based cohort. Gastroenterology 117, 49-57. doi: 10.1016/s0016-5085(99)70549-4

Sim, J. H., Ambler, W. G., Sollohub, I. F., Howlader, M. J., Li, T. M., Lee, H. J., et al. (2021). Immune cell-stromal circuitry in lupus photosensitivity. J. Immunol. 206, 302-309. doi: 10.4049/jimmunol.2000905

Sundberg, C., Ivarsson, M., Gerdin, B., and Rubin, K. (1996). Pericytes as collagenproducing cells in excessive dermal scarring. Lab. Invest. 74, 452-466.

Takeda, A., Hollmen, M., Dermadi, D., Pan, J., Brulois, K. F., Kaukonen, R., et al. (2019). Single-cell survey of human lymphatics unveils marked endothelial cell heterogeneity and mechanisms of homing for neutrophils. Immunity 51, 561.e5-572.e5.

Tamburini, B. A., Burchill, M. A., and Kedl, R. M. (2014). Antigen capture and archiving by lymphatic endothelial cells following vaccination or viral infection. Nat. Commun. 5:3989.
Tan, W., Zhang, W., Strasner, A., Grivennikov, S., Cheng, J. Q., Hoffman, R. M., et al. (2011). Tumour-infiltrating regulatory $\mathrm{T}$ cells stimulate mammary cancer metastasis through RANKL-RANK signalling. Nature 470, 548-553. doi: 10. 1038/nature09707

Tewalt, E. F., Cohen, J. N., Rouhani, S. J., Guidi, C. J., Qiao, H., Fahl, S. P., et al. (2012). Lymphatic endothelial cells induce tolerance via PD-L1 and lack of costimulation leading to high-level PD-1 expression on CD8 T cells. Blood 120, 4772-4782. doi: 10.1182/blood-2012-04-427013

Toomer, K. H., and Chen, Z. (2014). Autoimmunity as a double agent in tumor killing and cancer promotion. Front. Immunol. 5:116. doi: 10.3389/fimmu.2014. 00116

Turley, S. J., Cremasco, V., and Astarita, J. L. (2015). Immunological hallmarks of stromal cells in the tumour microenvironment. Nat. Rev. 15, 669-682. doi: $10.1038 /$ nri3902

Ulvmar, M. H., Werth, K., Braun, A., Kelay, P., Hub, E., Eller, K., et al. (2014). The atypical chemokine receptor CCRL1 shapes functional CCL21 gradients in lymph nodes. Nat. Immunol. 15, 623-630. doi: 10.1038/ni.2889

Veerman, K., Tardiveau, C., Martins, F., Coudert, J., and Girard, J. P. (2019). Singlecell analysis reveals heterogeneity of high endothelial venules and different regulation of genes controlling lymphocyte entry to lymph nodes. Cell Rep. 26, 3116.e5-3131.e5.

Veillette, A., Bookman, M. A., Horak, E. M., and Bolen, J. B. (1988). The CD4 and CD8 $\mathrm{T}$ cell surface antigens are associated with the internal membrane tyrosine-protein kinase p56lck. Cell 55, 301-308. doi: 10.1016/0092-8674(88) 90053-0

Vicente-Suarez, I., Larange, A., Reardon, C., Matho, M., Feau, S., Chodaczek, G., et al. (2015). Unique lamina propria stromal cells imprint the functional phenotype of mucosal dendritic cells. Mucosal Immunol. 8, 141-151. doi: 10.1038/mi.2014.51

Volkers, N. (1999). Do autoimmune diseases raise the risk of cancer? J. Natl. Cancer Inst. 91, 1992-1993. doi: 10.1093/jnci/91.23.1992

Wherry, E. J. (2011). T cell exhaustion. Nat. Immunol. 12, 492-499.

Wynn, T. A. (2007). Common and unique mechanisms regulate fibrosis in various fibroproliferative diseases. J. Clin. Invest. 117, 524-529. doi: 10.1172/jci31487

Xiang, M., Grosso, R. A., Takeda, A., Pan, J., Bekkhus, T., Brulois, K., et al. (2020). A single-cell transcriptional roadmap of the mouse and human lymph node lymphatic vasculature. Front. Cardiovasc. Med. 7:52. doi: 10.3389/fcvm.2020. 00052

Yamauchi, M., Barker, T. H., Gibbons, D. L., and Kurie, J. M. (2018). The fibrotic tumor stroma. J. Clin. Invest. 128, 16-25. doi: 10.1172/jci93554

Zhang, M., and Zhang, S. (2020). T cells in fibrosis and fibrotic diseases. Front. Immunol. 11:1142. doi: 10.3389/fimmu.2020.01142

Conflict of Interest: The authors declare that the research was conducted in the absence of any commercial or financial relationships that could be construed as a potential conflict of interest.

Copyright (c) 2021 Honan and Chen. This is an open-access article distributed under the terms of the Creative Commons Attribution License (CC BY). The use, distribution or reproduction in other forums is permitted, provided the original author(s) and the copyright owner(s) are credited and that the original publication in this journal is cited, in accordance with accepted academic practice. No use, distribution or reproduction is permitted which does not comply with these terms. 